\title{
Monitoring of Exercises Practice and Sports Performance - The use of Biomarkers for Monitoring and Control of Internal Training Loads
}

\author{
Helvio de Oliveira Affonso ${ }^{1,2 *}$ \\ ${ }^{1}$ Appto Physiology, Laboratory of Exercise, Nutrition and Sports Training, Vitória, Brazil \\ ${ }^{2}$ Pharmaceutical Sciences Graduate Program, Vila Velha University (UVV), Vila Velha, Brazil
}

Submission: may 03, 2019; Published: May 10, 2019

*Corresponding author: Helvio de Oliveira Affonso, Appto Physiology, Laboratory of Exercise, Nutrition and Sports Training, Vitória, Brazil

Abstract

Background: The level of innate ability and ability to respond to training with improved performance are basic in sport. However, the improvement in sports performance depends greatly on the optimization of distribution of the training and recovery loads prescribed to the athletes. Identifying what the "physiological price" of training and competitions is fundamental. Although numerous evolutions have been implemented in recent years, in favor of the development of sportsmen and athletes of high performance, protocols of follow-up, choice of periodization and distribution of training loads are still mostly reproductions and unproductive. Physiological adaptations are mostly monitored through external training load (ETL) and by rating of perceived exertion (RPE), by inaccuracy can generate important cumulative physiological wear and favor of illness in athletes and / or loss of performance for athletes. A systematic review of the literature evidences the relevant participation of the reactive oxygen species (ROS) as well as inflammatory responses during exercise. A new reflection then arises, the need to monitor the internal training load (ITL) from Biomarkers, making the training process more controlled, directly impacting less illness and more performance for the athletes.

Methods: "Bio flexible" model Periodization of training, from biochemical markers, oxidative stress and DNA fragmentation (ITL), together with performance parameters in the training (ETL).

Results: Emphasis for a World Record 50m Butterfly; Olympic gold medal 2016; World championship 2015 beach volleyball and 2018 second best time in the history of Brazil 10'02 100m athletics.

Keywords: Biomarkers; Sport Training; Monitoring; Performance; Illness

Abbreviations: ETL: External Training Load; RPE: Rating of Perceived Exertion; ROS: Reactive Oxygen Species; ITL: Internal Training Load

Introduction

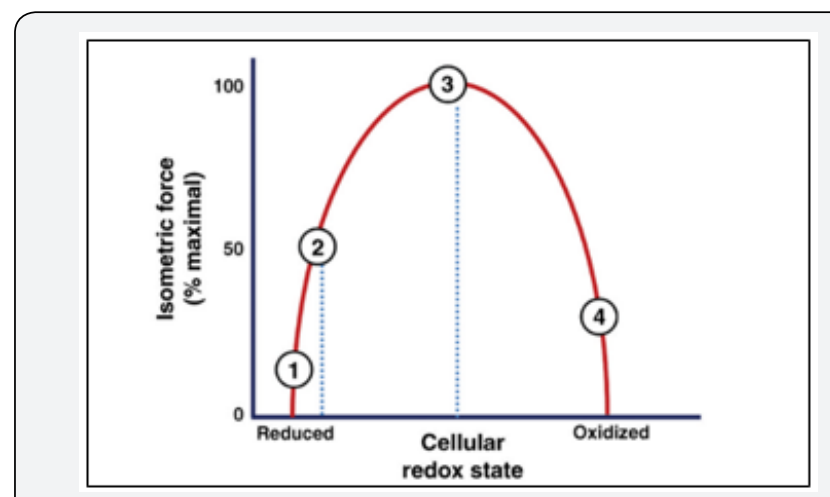

Figure 1: Adapted from Reid et al., 1993; Vollaard et al., 2005; Yavari et al, 2015; Reid, 2016; Becatti et al., 2017

In general, the quantification of the Internal Training Load is from the [Rating of Perceived Exertion (RPE)] and the training quantified by the scale of 6 to 20 of Borg Foster [1], Foster [2]. The value found multiplied by the time in training minutes and thus establish a scale for classification of the training session, posteriorly of the block and so on despite the undisputed control of this protocol, there are some questions about the reliability the values indicated by sportsmen or high-performance athletes in moments with higher levels of physiological and psycological stress. However, to ensure optimal exercise prescription for athletes and optimal training for high performance athletes, studies indicate that associated on RPE, the acute phase markers associated with oxidative stress markers along with the impact on DNA fragmentation may be better parameters Helvio[6]. In a systematic review of the literature this statement is justified with there is a relevant participation of the reactive oxygen species (ROS) as well as inflammatory responses during exercise 
(Pingitore et al., 2015, Davison et al., 2016). A new reflection then arises, the need to monitor the internal training load (ITC) Pingitore [3], Davison [4] its impact of forçe, power and performance Beccatti [5] (Figure 1).

\section{Conclusion}

The use of markers, markers of acute phase , mainly to define optimal intensities and volumes during specific training and some competitions; the use external loads always associated with internal loads; the establishing an individualized database of each athlete for future decision making based on individuality may favor better performance and avoid illness sportsrelated, such as ITRS (upper respiratory tract infections) and immunosuppression [6-12].

\section{References}

1. Foster C (1998) Monitoring training in athletes with reference to overtraining syndrome. Med Sci Sport Exerc 30(7): 1164-1168.

2. Foster C, Florhaug JA, Franklin J, Gottschall L, Hrovatin LA, et al. (2001) A new approach to monitoring exercise training. J Strength Condit Res 15(1): 109-115.

3. Pingitore A, Pereira Lima G, Mastorci F, Quinones A, Iervasi G, et al (2015) Exercise and Oxidative Stress: Potential Effects of Antioxidant Dietary Strategies in Sports, Nutrition.

4. Davison GW (2016) Exercise and Oxidative Damage in Nucleoid DNA Quantified Using Single Cell Gel Electrophoresis: Present and Future Application Front Physiol 7: 249.
5. Becatti M, Mannucci A, Barygina V, Mascherini G, Emmi G, et al. (2017) Redox status alterations during the competitive season in élite soccer players: focus on peripheral leukocyte-derived ROS. Intern Emerg Med 12(6): 777-788

6. The ofilidis G, Bogdanis GC, Koutedakis Y, Karatzaferi C (2018) Monitoring Exercise-Induced Muscle Fatigue and Adaptations: Making Sense of Popular or Emerging Indices and Biomarkers. Sports (Basel) 26: 6(4).

7. Andreatta MV, Curty VM, Coutinho JVS, Santos MÂA, Vassallo PF, et al. (2018) Cell-Free DNA as an Earlier Predictor of Exercise-Induced Performance Decrement Related to Muscle Damage. Int J Sports Physiol Perform 13(7): 953-956.

8. Affonso HO, Andreao FL, Porto ML, Meyrelles SS, Vasquez EC, et al. (2018) Nonconventional and conventional biomarkers evaluated in gold medalists beach volleyball players during the 2015 and 2016 seasons (pre-Olympic and Olympic years). Journal of physical education and sport 18: 1779.

9. Ryu JH, Paik IY, Woo JH, Shin KO, Cho SY, et al. (2016) Impact of different running distances on muscle and lymphocyte DNA damage in amateur marathon runners. J Phys Ther Sci 28(2): 450-455.

10. Powers SK, Jackson MJ (2008) Exercise-induced oxidative stress: cellular mechanisms and impact on muscle force production. Physiol Rev 88(4): 1243-1276.

11. Kocabaş R, Namiduru ES, Bagçeci AM, Erenler AK, Karakoç Ö, et al. (2016) The acute effects of interval exercise on oxidative stress and antioxidant status in volleyball players. J Sports Med Phys Fitness.

12. Clemente FM, Nikolaidis PT, Van der Linden CMI, Silva B (2017b) Effects of small-sided soccer games on internal and external load and lower limb power: a pilot study in collegiate players. Hum Mov 18: 5057.

\section{Your next submission with Juniper Publishers will reach you the below assets}

This work is licensed under Creativ

DOI: 10.19080/JPFMTS.2019.06.555688 